\title{
Now we NO
}

\author{
Nitric oxide (NO) is an important signalling molecule in biological systems, but it is unclear exactly how \\ it interacts with some metalloproteins. Now, a collection of articles in this issue reveal how NO binds to \\ proteins containing type-1 copper sites.
}

In 1998 the Nobel Prize in Physiology or Medicine was awarded to Robert F. Furchgott, Louis J. Ignarro and Ferid Murad 'for their discoveries concerning nitric oxide as a signalling molecule in the cardiovascular system'1. Their research had shown that $\mathrm{NO}$, a relatively reactive compound that is a gas under standard conditions, is used to transmit cellular signals in mammals. NO is now known to be involved in a variety of important biological processes; it acts as a signalling molecule in the nervous system, as a vasodilator in the cardiovascular system, and it is produced as a weapon by the immune system to fight against infections ${ }^{2-4}$. Despite impressive advances in our knowledge of the biological functions mediated by NO, how it interacts with its biomolecular targets is not always fully clear.

One way in which NO is known to interact with metalloproteins is the through the direct coordination of the nitrogen atom with a metal centre to form a metal-nitrosyl complex. This type of species is involved in a range of biological processes, including $\mathrm{NO}$ sensing by soluble guanylate cyclase (an NO receptor) and inhibition of cytochrome $c$ oxidase $^{3}$. In both of these cases NO interacts with an iron centre; however, NO also binds reversibly to type- 1 copper sites in proteins such as ceruloplasmin, ascorbate oxidase, azurin and halocyanin ${ }^{5-7}$, but the mechanism that underpins this binding, and the structures of the NO-bound complexes, are not known. The structures could involve the formation of a direct bond between copper and the nitrogen of the NO to form a metal-nitrosyl complex - which would be similar to the structure observed in many iron proteins. Alternatively, instead of end-on binding, NO could bind to the copper in a side-on manner such as observed in the crystal structure of fully reduced bovine cytochrome $c$ oxidase $e^{8}$. Another possibility is that NO could react with a cysteine residue to form an $S$-nitrosothiol adduct, which has also been observed in some haem proteins $s^{9,10}$.

In an Article in this issue on page 663, a team led by Nihan Çelebi-Ölçüm and Timothy H. Warren report the synthesis of a small-molecule complex that mimics the environment around the metal in a type- 1 copper centre and then probe its reactivity with NO. Tris(pyrazolyl)borate copper(II) thiolates (which contain a TpCu-SR motif) have been used as a mimic of type-1 copper sites before ${ }^{11-12}$, but although such complexes could be reacted with $\mathrm{NO}$ at low temperatures, the products were thermally unstable and could not be unambiguously characterized. In an effort to improve the stability of the system, the team led by Çelebi-Ölçüm and Warren switched to a less electron-donating ligand system containing mesityl (Mes) groups. Exposing the

${ }^{\mathrm{Mes}} \mathrm{TpCu}{ }^{\mathrm{II}}-\mathrm{SCPh}_{3}$ complex to NO enabled the product to be identified as an $S$-nitrosothiol adduct ${ }^{{ }^{M e s}} \mathrm{TpCu}^{\mathrm{I}}\left(\kappa^{1}-\mathrm{N}(\mathrm{O}) \mathrm{SCPh}_{3}\right)$ using $\mathrm{X}$-ray crystallography. This adduct showed reversible loss and recapture of $\mathrm{NO}$, thus mimicking the reactivity of type- 1 copper sites in proteins. Çelebi-Ölçüm, Warren and co-workers also suggest that this binding motif could represent another strategy to reversibly interconvert $\mathrm{NO}$ and RSNOs.

The binding of $\mathrm{NO}$ in biological systems - and its effects on structure, properties and reactivity - can also be studied using model proteins. This is the approach reported in a second Article in this issue (page 670) that looks at the binding of NO in an engineered copper protein - a variant of azurin. It is known that wild-type azurin reacts with NO (ref. 7), but the resulting adduct is only fully formed at very low temperatures. Now, a team led by Ninian J. Blackburn, Edward I. Solomon and Yi Lu build on their previous experience ${ }^{13,14}$ of redesigning the coordination environments and tuning the reactivity of metalloproteins to make an azurin variant that more closely mimics the more open copper centre of nitrosocyanin. Nitrosocyanin is a copper protein that is thought to be involved in the denitrification process, but is difficult to study because it has not yet been recombinantly expressed.

The Article from Blackburn, Solomon, Lu and co-workers describes how the primary coordination sphere can be altered - and the reduction potential of the copper centre in an azurin tuned - to create a variant protein that can bind $\mathrm{NO}$ under more physiologically relevant conditions. Using a battery of spectroscopic techniques, such as $\mathrm{UV}-\mathrm{vis}$ absorption, electron paramagnetic resonance and extended X-ray absorption fine structure, the reversible insertion of $\mathrm{NO}$ into a copper-thiolate bond was studied. The results provide the first direct evidence of $S$-nitrosylation of a $\mathrm{Cu}$ (II)-bound cysteine residue in metalloproteins.

The complementary nature of these two approaches to studying the biological role of $\mathrm{NO}$ - and the results that they generated - are discussed in an accompanying News \& Views article by Subhra Samanta and Nicolai Lehnert on page 639. They also explain that previously it was thought that the most probable structure formed in these systems was a simple $\mathrm{Cu}(\mathrm{II})-\mathrm{NO}$ complex and that the identification of the $S$-nitrosothiol adduct was surprising. Finally they discuss the implications of these results for buffering NO concentrations and consider a mechanism by which NO could regulate the activity of blue copper proteins involved in denitrification and related processes.

Although there is still much to be learned about physiologically relevant interactions of $\mathrm{NO}$, the studies reported in this issue nicely showcase how chemical synthesis and protein engineering can both be utilized to unravel the secrets of biomolecular interactions. Together these studies have revealed a wealth of information about the mechanism of binding between NO and type-1 copper sites and the structures that are formed.

\footnotetext{
References

1. The Nobel Prize in Physiology or Medicine 1998. Nobelprize.org; http://go.nature.com/1RV7mMr

2. Cary, S. P. L., Winger, J. A., Derbyshire, E. R. \& Marletta, M. A Trends Biochem. Sci. 31, 231-239 (2006).

3. Hunt, A. P. \& Lehnert, N. Acc. Chem. Res. 48, 2117-2125 (2015).

4. Moncada, S., Palmer, R. M. \& Higgs, E. A. Pharmacol. Rev. 43, 109-142 (1991)

5. Wever, R., Van Leeuwen, F. X. R. \& Van Gelder, B. F Biochim. Biophys. Acta 302, 236-239 (1973).

6. Van Leeuwen, F. X. R., Wever, R., Van Gelder, B. F., Avigliano, L. \& Mondovi, B. Biochim. Biophys. Acta 403, 285-291 (1975).

7. Ehrenstein, D., Filiaci, M., Scharf, B., Engelhard, M. \& Nienhaus, G. U. Biochemistry 34, 12170-12177 (1995). 8. Ohta, K. et al. Acta Crystallogr. F 66, 251-253 (2010).

9. Weichsel, A. et al. Proc. Natl Acad. Sci. USA 102, 594-599 (2005)

10. Schreiter, E. R., Rodríguez, M. M., Weichsel, A., Montfort, W. R. \& Bonaventura, J. J. Biol. Chem. 282, 19773-19780 (2007).

11. Kitajima, N., Fujisawa, K., Tanaka, M. \& Morooka, Y. J. Am. Chem. Soc. 114, 9232-9233 (1992).

12. Qiu, D., Kilpatrick, L., Kitajima, N. \& Spiro, T. G. J. Am. Chem. Soc. 116, 2585-2590 (1994).

13. Marshall, N. M. et al. Nature 462, 113-116 (2009).

14. Liu, J. et al. J. Am. Chem. Soc. 136, 12337-12344 (2014).
} 